\title{
O JOGO RITUAL E AS PEDAGOGIAS DO SUL: PRÁTICAS PEDAGÓGICAS PARA A DESCOLONIZAÇÃO DO ENSINO DO TEATRO
}

\section{The ritual play and the pedagogies of the south: pedagogical practices for the decolonization of the teaching of theater}

\author{
Robson Carlos Haderchpek ${ }^{1}$ \\ Universidade Federal do Rio Grande do Norte - UFRN
}

Resumo: Este artigo discute a prática da educação bancária presente no ensino do teatro no Brasil e desenvolve um recorte epistemológico trazendo à luz uma experiência de ensino do teatro desenvolvida no âmbito da UFRN com o Grupo Arkhétypos. A partir de uma metodologia empírica de caráter experimental o grupo desenvolve uma prática com a poética dos elementos, o jogo ritual e reflete sobre a importância das pedagogias do sul.

Palavras-chave: Práticas Pedagógicas; Jogo Ritual; Epistemologias do Sul.

Abstract: This article discusses the practice of banking education present in the teaching of theater in Brazil and develops an epistemological clipping bringing to light an experience of teaching theater developed within the scope of UFRN with the Arkhétypos Group. From an empirical methodology of experimental character the group develops a practice with the poetics of the elements, the ritual play and reflects about the importance of the pedagogies of the south.

Keywords: Pedagogical Practices; Ritual Play; Epistemologies of the South.

${ }^{1}$ Programa de Pós-Graduação em Artes Cênicas da UFRN.

Revista Moringa - Artes do Espetáculo, João Pessoa, UFPB, v. 9 n. 1, jan/jun 2018, p. 55 a 65

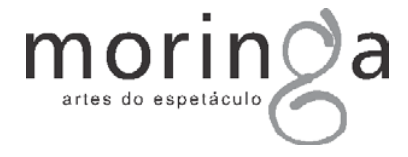


A fim de instaurarmos uma reflexão acerca das pedagogias da cena é importante reconhecer o modelo de ensino que impera na contemporaneidade brasileira. Convém considerar que nós somos fruto de um processo de colonização que teve início no final do século XV e início do século XVI, e desde esta época somos guiados por um modelo de educação colonizada. Cientes desta situação histórico-social e reconhecendo que nós temos um modelo de educação colonizado, a questão que paira sobre nossas cabeças é: como desenvolver uma pedagogia teatral que transcenda 0 modelo do colonizador?

Há cerca de quinhentos anos vimos reproduzindo nas escolas o que o pedagogo brasileiro Paulo Freire (1996) chama de "educação bancária", uma educação em que o aluno senta-se no banco de forma passiva e o professor the transfere o conhecimento. $\mathrm{Na}$ tentativa de romper com este modelo Freire nos propõe uma alternativa:

É isto que nos leva, de um lado, à crítica e à recusa ao ensino "bancário", de outro, a compreender, que apesar dele, o educando a ele submetido não está fadado a fenecer; em que pese o ensino "bancário", que deforma a capacidade criativa do educando e do educador, o educando a ele sujeitado pode, não por causa do conteúdo cujo "conhecimento" Ihe foi transferido, mas por causa do processo mesmo de aprender, dar, como se diz na linguagem popular, a volta por cima e superar o autoritarismo e o erro epistemológico do "bancarismo". (1996, p. 25)

É no processo, na relação entre o aprender e o ensinar que se estabelece entre o professor e o educando, que se encontra a chave para romper com este sistema de educação autoritário e unilateral, é preciso repensar a prática pedagógica a partir dos sujeitos que a compõe e lembrar que os processos educativos são vias de mão dupla.

[...] embora diferentes entre si, quem forma se forma e re-forma ao formar e quem é formado forma-se e forma ao ser formado. É neste sentido que ensinar não é transferir conhecimentos, conteúdos, nem formar é ação pela qual o sujeito criador dá forma, estilo ou alma a um corpo indeciso e acomodado [...] Quem ensina aprende ao ensinar e quem aprende ensina ao aprender. (FREIRE, 1996, p.23)

Apesar dos numerosos esforços de pesquisadores da área do Teatro e da Educação para romper com este modelo, o campo da pedagogia teatral ainda reproduz 0 mesmo modelo. Muitos professores de teatro, nas diversas instâncias educacionais acreditam que devem ensinar os conteúdos do teatro aos seus alunos, e para tanto se apóiam no modelo do teatro europeu, herdado no processo de colonização.

Seria ingênuo pensar num teatro que não tivesse a influência do teatro europeu, visto que o colonizador chegou ao Brasil se utilizando do teatro para catequizar os índios. E desde então, vimos reproduzindo inconscientemente este modelo de catequização nos palcos brasileiros.

Geralmente quando perguntamos a uma pessoa que estuda teatro o que ela está aprendendo ela responde o nome de um autor, de um dramaturgo ou de um pensador do teatro europeu ou russo. Vez por outra encontramos alguém que diz estudar as linguagens provenientes do teatro oriental, entretanto, o ponto chave da discussão não é a origem dos estudos teatrais, e sim a origem 
de um pensamento sobre teatro que é formulado a partir de padrões externos à nossa cultura.

Dito isto surge uma segunda questão: mas, se - Brasil é um país miscigenado, como podemos pensar num modelo de teatro que seja genuinamente brasileiro? Seria possível pensar numa forma teatral diretamente relacionada à nossa raiz ancestral?

Antes dos colonizadores chegarem à Terra de Santa $\mathrm{Cruz}^{2}$, uma variedade de etnias indígenas habitava este local. Será que estes povos não realizavam nenhum rito? Será que eles também não adoravam os seus deuses como faziam os povos da Grécia na antiguidade clássica? Com o processo de colonização e posteriormente com o processo de escravidão, o Brasil dizimou boa parte da sua população indígena que hoje sobrevive em reservas demarcadas pela FUNAI e que muitas vezes são desrespeitadas pelos grandes fazendeiros e latifundiários. Não é raro também ouvir a notícia de que inundaram uma reserva indígena para construir uma hidrelétrica, e assim, junto com as águas que afogam milhares de animais e plantas, afogam-se também os saberes de um povo que mais uma vez é expulso de suas terras e posto à margem como algo descartável.

Desde que fomos colonizados vimos reproduzindo um conhecimento estanque que vem importado dos modelos europeus, o teatro que conhecemos hoje é fortemente arraigado nas tradições do teatro europeu e do teatro russo. Muitos estudam Stanislavski, Brecht, Meyerhold, Grotowski, Eugênio Barba,

2 Primeiro nome dado ao Brasil pela esquadra de Pedro Álvares Cabral.
Shakespeare, Commedia dell'arte, etc.. Mas, será que o teatro brasileiro não poderia ser algo para além disso? Não existe teatro para além da Grécia e da Europa? Sim, alguns pesquisadores teatrais como Eugênio Barba (2012) foram estudar as raízes do teatro balinês, e das danças orientais, mas será que o chamamos hoje de teatro é teatro? Será que não haveria outra forma de se pensar o teatro? Será que não haveria outro teatro?

Mais do que apresentar respostas este artigo busca desencadear uma reflexão. Segundo o pesquisador e pedagogo espanhol Jorge Larrosa, estamos vivendo um momento histórico em que mais importante do que encontrar as respostas, o essencial é refazer as perguntas:

Penso que o maior perigo para a
Pedagogia de hoje está na arrogância dos
que sabem, na soberba dos proprietários
de certezas, na boa consciência dos
moralistas de toda a espécie, na
tranqüilidade dos que já sabem o que
dizer aí ou o que se deve fazer e na
segurança dos especialistas em repostas
e soluções. Penso, também, que agora o
urgente é recolocar as perguntas,
reencontrar as dúvidas e mobilizar as
inquietudes. (2006, p. 08) Desde 2010, ano em que me tornei professor no Curso de Licenciatura em Teatro da UFRN, venho refletindo sobre minha prática pedagógica e me recolocando algumas perguntas. Quando cheguei na citada Universidade assumi as disciplinas da área de Atuação e tive que lecionar os conteúdos do teatro clássico ocidental: teatro realista e teatro épico. Sempre procurei em minhas aulas fazer uma ponte entre a teoria estudada - ações físicas, análise ativa, circunstâncias dadas, 
efeito de distanciamento, gestus social, etc. - e a realidade brasileira. Contudo, sempre me intrigava 0 fato dos alunos necessariamente terem que revisitar sistematicamente estes conteúdos.

Anos depois, em 2013, já como coordenador do Curso de Teatro propus uma reforma curricular que permitiu uma maior abertura para os saberes locais, manifestações populares e criações artísticas híbridas, entre a dança e o teatro, entre o teatro e a música e entre 0 teatro e o ritual. Foi neste momento que comecei a sistematizar uma prática pedagógica junto ao Grupo Arkhétypos, grupo de pesquisa e extensão da Universidade Federal do Rio Grande do Norte que dialoga em ampla medida com os Cursos de Graduação em Teatro e Pós-Graduação em Artes Cênicas. A esta prática pedagógica demos o nome de poética dos elementos.

\section{A Poética dos Elementos}

Desde a sua criação em 2010 o Grupo Arkhétypos vem trabalhando numa perspectiva laboratorial e tem construído seus espetáculos a partir de um mergulho no universo simbólico de cada ator, sempre associando a prática artística com a busca pelo autoconhecimento. É comum em seus processos de criação ${ }^{3}$ que o Grupo escolha um elemento da natureza como mote criativo: terra, água, fogo e ar. Chamamos este trabalho de poética dos elementos, inspirados por Gaston Bachelard (2013) que escreve

\footnotetext{
${ }^{3}$ Cada um dos processos de criação de criação do Grupo Arkhétypos foi guiado por um dos elementos da natureza, e a partir da poética dos elementos foram construídos quatro espetáculos: Santa Cruz do Não Sei (2011) que foi inspirado pela água, Aboiá (2013) que foi guiado pela terra, Revoada (2014) que foi conduzido pelo ar, e Fogo de Monturo (2015) que foi alimentado pelo fogo.
}

sobre a imaginação da matéria, passando pela tetralogia dos elementos:

\begin{abstract}
Com efeito, acreditamos possível estabelecer, no reino da imaginação, uma lei dos quatro elementos, que classifica as diversas imaginações materiais conforme elas se associem ao fogo, ao ar, à água ou à terra. $E$, se é verdade, como acreditamos, que toda matéria deve receber componentes - por fracos que sejam - de essência material, é ainda essa classificação pelos elementos materiais fundamentais que deve aliar mais fortemente as almas poéticas. Para que um devaneio tenha prosseguimento com bastante constância para resultar em uma obra escrita, para que não seja simplesmente a disponibilidade de uma hora fugaz, é preciso que ele encontre sua matéria, é preciso que um elemento material Ihe dê sua própria substância, sua própria regra, sua poética específica. (BACHELARD, 2013, p. 3-4)
\end{abstract}

Através desta substância material, própria da imaginação, buscamos potencializar os diferentes tipos de energia provenientes de um processo de criação, sempre tomando como referência um universo simbólico de dimensões arquetípicas. Com base neste princípio, a busca dos atores do Grupo Arkhétypos segue no sentido de encontrar metáforas que possam reconectar o homem com os eternos universais, religando-os à essência da imaginação material (BACHELARD, 2013).

Dentro de um processo de criação de natureza ritualística 0 ator torna-se um canal de manifestação das paixões, criando fissuras no tempo e no espaço e permitindo que o inconsciente coletivo (JUNG, 2012) se revele através das figuras arquetípicas/personagens que se materializam no "jogo ritual". 
Compartilham deste pensamento os professores Patricia Bélières e Alejandro Cancela, fundadores da Escuela de Interpretación Bélières-Cancela da Argentina e autores do livro El cantante popular y la interpretación: Una proposta metodológica integradora de saberes (2013). Os pesquisadores vieram ao Brasil em 2016 participar do Intercâmbio Latino Americano de Teatro Ritual, realizado na UFRN, e partilharam com os docentes e discentes sua visão metodológica sobre a poética dos quatro elementos.

Os pesquisadores argentinos, tal como nós do Grupo Arkhétypos, se pautam no conceito de imaginação material proposto pelo filósofo Gaston Bachelard a fim de elaborarem a sua proposta pedagógica. Para eles cada um dos quatro elementos corresponde a uma particular imagem afetiva e uma apreensão própria da realidade:

Nas imagens poéticas, os quatro elementos não estão separados de forma rígida, mas podem ser relacionados; ar e fogo, por exemplo, tem elevação, ascensão. Do mesmo modo, cada um deles corresponde a uma rede particular de imagens afetivas e a uma apreensão da natureza e da matéria. Os quatro elementos nos farão viajar através de um rico mundo simbólico. ${ }^{4}$ (BÉLIĖRES e CANCELA, 2013, p. 39)

\section{Para os pesquisadores Bélières e Cancela 0} estudo da poética dos elementos é fruto de uma proposta integradora de saberes:

Até agora consideramos os quatro elementos a partir de diferentes abordagens: pensamento ocidental,

\footnotetext{
4 Tradução livre do autor.
}

astrologia, pensamento oriental e a visão particular de Gaston Bachelard. Adicionamos a isso a contribuição enriquecedora dos Centros Energia. Agora, como integrar esse conhecimento para nosso propósito - o fato artístico - e mais particularmente, para a interpretação na música popular? ${ }^{5}(2013$, p.47)

O trabalho dos dois pesquisadores é direcionado principalmente para cantores, mas eles trabalham também com atores e dançarinos. Eles dão vários cursos itinerantes e já estiveram em várias partes do mundo compartilhando a metodologia elaborada por eles.

O foco principal do trabalho desenvolvido pelos dois pesquisadores são os Centros de Energia, mais conhecidos como chakras ${ }^{6}$, e eles associam os chakras ao trabalho com os elementos. Para fazer isso eles se apóiam no que há de mais concreto no trabalho do ator, o corpo:

Vamos começar com o mais concreto: o
corpo. Os quatro elementos não precisam
ser adquiridos porque já estão em nós; só
precisamos "lembrá-los", levá-los à
consciência. Não há nada esotérico neles.
[...] Como professores, começamos,
então, com uma realidade concreta:
usamos uma linguagem simples (terra,
fogo, água e ar são termos que todos
conhecemos) e trabalhamos a partir do

\footnotetext{
5 Tradução livre do autor.

6 No livro El cantante popular y la interpretación: Una proposta metodológica integradora de saberes (2013) Patricia Bélières e Alejandro Cancela nos apresentam os sete chakras: Muladhara chakra (centro bajo), Swadishthana chakra (centro lumbo-sacro), Manipura chakra chakra (centro medio), Anatha chakra (centro cardíaco), Visuddha chakra (centro laríngeo), Ajna chakra (centro frontal) e Sahasrara chakra (centro coronário). No trabalho dos pesquisadores argentinos o primeiro chakra é associado ao elemento terra, o segundo e o terceiro ao elemento fogo, o quarto ao elemento água e os três últimos ao elemento ar.
} 
corpo. $\mathrm{O}$ aluno pode, assim, reconhecer a sua terra, o fogo, a água e o ar no corpo e na voz. ${ }^{7}$ (BÉLIÈRES e CANCELA, 2013, p. 47)

No Grupo Arkhétypos nós também trabalhamos a partir do corpo, mas ativamos essa energia dos chakras através de um "estado alterado de consciência" que é decorrente do "jogo ritual". O nosso processo é desencadeado por um dispositivo inconsciente que permite que cada ator dentro do processo também descubra a sua terra, o seu fogo, a sua água e o seu ar.

Entendemos que cada pessoa traz uma qualidade de água, de fogo, de terra e de ar, e que cada um destes elementos apresenta nuances que variam de acordo com as experiências individuais de cada indivíduo. $\mathrm{E}$ este conteúdo vem sendo atualmente trabalhado nas disciplinas de Jogo e Cena I e Atuação III, respectivamente no primeiro e no quarto semestre do Curso de Licenciatura em Teatro.

\section{O Jogo Ritual}

Há três anos o conceito de "jogo ritual" vem sendo pesquisado pelo Grupo Arkhétypos, que toma por base os princípios ritualísticos da cena. Para formular este conceito partimos de uma definição de Grotowski que diz:

O teatro era (e permaneceu, mas em um âmbito residual) algo como um ato coletivo, um jogo ritual. No ritual não há atores e não há espectadores. Há participantes principais (por exemplo, o xamã) e secundários (por exemplo, a multidão que observa as ações mágicas do xamã e as acompanha com a magia

\footnotetext{
7 Tradução livre do autor.
}

dos gestos, do canto, da dança etc.). (2007, p. 41, grifo nosso)

O "jogo ritual" origina-se dessa ideia do Grotowski (2007) da não separação entre atores e espectadores. O "jogo ritual" não pode ser considerado um "jogo dramático"8 (LOPES, 1989) porque o "jogo ritual" é feito para ser visto e o jogo dramático convencional é feito para se jogado por todos. Dentro do "jogo ritual" nós convidamos o público para observar as ações mágicas do ator e entrar na história com ele. Também não podemos dizer que o "jogo ritual" seja um "jogo teatral" (JAPIASSU, 2001), pois no jogo teatral convencional existe uma separação clara entre 0 ator e o espectador. De acordo com Ricardo Japiassu:

Os jogos teatrais são procedimentos lúdicos com regras explícitas. Para entender a diferença entre o jogo teatral e o jogo dramático, é preciso lembrar que a palavra theatron, que significa "local de onde se vê" (platéia). Já a palavra drama, também oriunda da língua grega, quer dizer "eu faço, eu luto" (Slade, 1978, p.18). No jogo dramático entre sujeitos, portanto, todos são fazedores da situação imaginária, todos são "atores". No jogo teatral, o grupo pode se dividir em equipes que se alternam nas funções de "jogadores" e "observadores", isto é, os sujeitos jogam deliberadamente para outros que os observam. (2001, p. 25)

No caso do "jogo ritual", todas essas opções são possíveis. O que o "jogo ritual" retoma é a origem primitiva do jogo e propõe uma situação entre, ou seja, um jogo em que o espectador é convidado a observar e a interagir com a cena, emancipando-o da

\footnotetext{
${ }^{8}$ Em seu livro Pega Teatro (1989) Joana Lopes defende a perspectiva do jogo dramático espontâneo, em que todos são atuantes, mas nem todos se tornam atores. Vivenciar a experiência teatral faz parte dos processos de metamorfose do sujeito, mas nem todos escolhem 0 caminho do teatro como profissão.
} 
situação de mero espectador e atribuindo-lhe o papel de viver o sentido da cena junto com o ator. Na proposta do "jogo ritual" as fronteiras entre palco e plateia são borradas e o público participante integra 0 ato de comunhão ritualístico completando o sentido da ação, assumindo o papel de espectador emancipado (RANCIÈRE, 2002).

Este tipo de jogo remete a uma ação própria dos rituais dos povos antigos, povos estes que habitavam a América antes da colonização e que traziam saberes que podem e devem ser resgatados.

No Grupo Arkhétypos e nas disciplinas de Jogo e Cena I e Atuação III nós buscamos nos reconectar com esses saberes trabalhando numa perspectiva de jogo que parte do encontro do ator com si mesmo, com o seu universo interior, e o coloca numa dimensão limiar, que será compartilhada posteriormente com o público. Por isso, o "jogo ritual" se aproxima mais da festa e da dança do que do teatro propriamente dito. É tal como coloca Johan Huizinga:

Existem entre a festa e o jogo, naturalmente, as mais estreitas relações. Ambos implicam uma eliminação da vida cotidiana. Em ambos predominam a alegria, embora não necessariamente, pois também a festa pode ser séria. Ambos são limitados no tempo e no espaço. Em ambos encontramos uma combinação de regras estritas com a mais autêntica liberdade. Em resumo, a festa e o jogo têm em comum suas características principais. $\mathrm{O}$ modo mais íntimo de união entre ambos parece encontrar-se na dança. (2010, p. 25)

No nosso caso, como trabalhamos na perspectiva do Teatro Ritual, nós criamos num limiar entre a dança e o teatro, entre o teatro e a música e entre todos estes e o ritual, por isso o termo "jogo ritual" tem refletido a nossa busca cênica e a nossa proposta pedagógica. O "jogo ritual" retoma a origem primitiva do jogo e o coloca numa categoria anterior à divisão entre jogo dramático e jogo teatral.

Dentro do círculo do jogo, as leis e costumes da vida quotidiana perdem a validade. Somos diferentes e fazemos coisas diferentes. Esta supressão temporária do mundo habitual é inteiramente manifesta no mundo infantil, mas não é menos evidente nos grandes jogos rituais dos povos primitivos. (HUIZINGA, 2010, p. 15-16)

Os saberes dos povos primitivos podem ser resgatados então a partir de uma prática pedagógica que transcende os sabres do colonizador europeu nos colocando em diálogo com uma dimensão que está para além do conceito de teatro e para além de uma técnica: a dimensão da experiência e da troca.

Se o ator e/ou o bailarino não estiverem abertos para o "jogo ritual" ele não acontece, e estamos tratando aqui de uma espécie de "estado alterado de consciência", ou um tipo de "transe consciente". De fato não há uma perda da consciência, o que acontece é uma imersão tão grande do ator/bailarino nessa suspensão do tempo que ele deixa de seguir a sua lógica convencional cotidiana e passa a adotar uma lógica ficcional, uma lógica ancestral, que transcende a ideia da personalidade, do eu interior e atinge uma dimensão arquetípica, universal.

Em seu livro Grotowski estados alterados de consciência: teatro, máscara, ritual a autora Joice Aglae Brondani reúne uma série de 
artigos que discutem os "estados alterados de consciência" no trabalho do ator. Um artigo em especial escrito por Giuliano Campo, professor em Drama pela Universidade de Ulster na Irlanda do Norte "A Arte do Ator e a Possessão: os estados alterados de consciência (asc) nas suas inter-relações com o teatro" fala sobre os vários tipos de transe construindo uma gradação. No caso do "jogo ritual" o tipo de transe oscila entre 0 transe avançado do quarto tipo e o transe do ritual de possessão (CAMPO apud BRONDANI, 2015, p. 89).

Cada participante dentro do "jogo ritual" tem um percurso muito particular, e ao fazer suas escolhas, o ator/bailarino acessa imagens do seu inconsciente concretizando-as e/ou traduzindo-as no seu corpo. E é na busca da compreensão do significado destas imagens que o jogo de fato se instaura, pois, dentro de um universo infinito de probabilidades, uma imagem material se manifesta no processo de criação gerando um sentido e trazendo à tona um manancial de significados que vão povoar a imaginação do intérprete, e em seguida a do espectador.

Trabalhamos com as Artes do Corpo, da Dança e do Teatro e nos desafiamos a transcender os limites de um e de outro para nos encontrarmos numa região entre, numa zona de encontros onde o que o impera é a sabedoria das cadeias mágicas capaz de reconectar $\mathrm{o}$ ator e o espectador com a cena, é tal como diz Artaud:

Saber antecipadamente que pontos do corpo é preciso tocar significa jogar o espectador nos transes mágicos. É [dessa] espécie preciosa de ciência que a poesia no teatro há muito se desacostumou. Conhecer as localizações do corpo é, portanto, refazer a cadeia mágica. E com o hieróglifo de uma respiração quero reencontrar uma ideia de teatro sagrado. (ARTAUD, 1993, p.149-150)

Este experiência desenvolvida no âmbito da UFRN nos permitiu re-encontrar o sentido primordial da cena, sentido este anterior ao conceito de teatro que nos foi trazido pelo colonizador europeu, e a partir desta experiência e desta mudança de perspectiva, pudemos redimensionar tanto a nossa prática artística quanto pedagógica.

\section{Pedagogias do Sul}

Uma das reflexões mais importantes que surgiu ao longo desta experiência da UFRN se deu quando nos demos conta de que não estávamos falando de uma pedagogia teatral, mas sim de pedagogias teatrais.

Ao longo dos últimos 12 anos atuando no ensino superior, pude perceber que cada qual, dentro da sua perspectiva e da sua realidade desenvolve uma pedagogia, ou seja, o nosso fazer teatral é múltiplo, variado e inclui no seu modo de fazer uma série de procedimentos que estão diretamente relacionados com o sujeito, ou com os sujeitos que integram este fazer. Por isso, não há como se pensar numa "educação bancária" dentro do teatro e não se pode querer que todos façam o mesmo tipo de teatro.

Durante os últimos anos tem-se focado muito na questão da técnica, como algo que pode ser partilhado e universalizado. Contudo, é salutar considerar que toda técnica é datada e cada técnica diz respeito a um contexto histórico e cultural específico, por isso, nem sempre o que serve a um serve a todos e esta ideia de universalização está equivocada. É tal

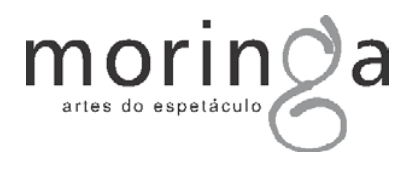


como coloca Paulo Freire: "[...] transformar a experiência educativa em puro treinamento técnico é amesquinhar o que há de fundamentalmente humano no exercício educativo: o seu caráter formador." (FREIRE, 1996, p. 33). Precisamos romper com este pensamento colonizado e descobrir novos modos de fazer.

No teatro todo modo de fazer está intimamente relacionado a um modo de pensar, ou seja, toda prática cênica está relacionada a um conhecimento, a uma teoria que se faz carne na efemeridade da cena. Por isso, é de fundamental importância dar espaço ao novo e repensar as pedagogias da cena transcendendo essa ideia de técnica.

O teatro europeu vem há muito tempo difundindo os mesmos princípios, e nós sem exercermos o nosso senso crítico, vimos reproduzindo os mesmos modelos sem nos darmos conta da riqueza que temos em nossa terra, dos saberes que estão presentes em cada região do país e dos modos de fazer que emergem de realidades tão distintas.

É muito difícil se pensar numa arte brasileira, num teatro brasileiro, numa pedagogia teatral brasileira se não pensarmos os diversos brasis que temos dentro do Brasil. Precisamos valorizar os saberes da nossa gente, da nossa cultura, da cidade onde moramos e revisitar os saberes que foram relegados e desconsiderados pelos colonizadores.

Convidando-nos a revisitar esses saberes o sociólogo Boaventura de Sousa Santos nos propõe um mergulho nas epistemologias do sul. Segundo Boaventura (2009) não há epistemologias neutras, para ele a reflexão epistemológica deve incidir não somente sobre os conhecimentos abstratos, mas sob as práticas de conhecimento e seus impactos nas práticas sociais:
É à luz delas que importa questionar o impacto do colonialismo e do capitalismo modernos na construção das epistemologias dominantes. O colonialismo, para além de todas as dominações porque é conhecido, foi também uma dominação epistemológica, uma relação extremamente desigual de saber-poder que conduziu à supressão de muitas formas de saber próprias dos povos e nações colonizados, relegando muitos outros saberes para um espaço de subalternidade. (SANTOS; MENESES, 2009, p.07)

Quando Boaventura fala das epistemologias do sul, ele fala da metáfora ${ }^{9}$ de um sul colonizado, fala de um campo de desafios epistêmicos que procuram ganhar voz diante dos danos e impactos historicamente causados pelo capitalismo. Boaventura define as epistemologias do sul da seguinte forma:

Trata-se do conjunto de intervenções epistemológicas que denunciam a supressão dos saberes levada a cabo, ao longo dos últimos séculos, pela norma epistemológica dominante, valorizam os saberes que resistiram com êxito e as reflexões que estes têm produzido $\mathrm{e}$ investigam as condições de um diálogo entre conhecimentos. (SANTOS; MENESES, 2009, p. 07)

\footnotetext{
9 Ao falar das epistemologias do sul Boaventura (2009) não se refere a uma localização geográfica, mas sim a um conhecimento que foi colocado à margem, que foi esquecido e/ou desconsiderado. O conhecimento do sul pode estar localizado geograficamente no norte do globo terrestre, como o é o caso do México, por exemplo, que guarda heranças históricas da cultura Maia, mas ainda sim traz um conhecimento próprio do sul.
} 
É na busca de um diálogo horizontal de conhecimentos que seguimos pelos caminhos da pedagogia teatral e nos propomos a repensar este fazer teatral contemporâneo que relega os saberes das manifestações populares e os sabres do povo deste lugar.

Muitos professores de teatro, diretores e pedagogos ainda pautam o seu fazer artísticopedagógico num modelo de teatro que tem uma dramaturgia, um texto e uma técnica específica. Grande parte desses professores acredita que existe um "jeito certo" de se fazer teatro e que este "jeito certo" reflete os moldes de um teatro europeu, fundamentado numa técnica e numa linguagem vanguardista. Uma grande maioria acredita que ensinar teatro é transferir um conhecimento, ou seja, reproduzir a prática da "educação bancária".

Será que não podemos pensar numa arte teatral e numa pedagogia que se constroem junto com os sujeitos envolvidos na ação? Será realmente que existe um "jeito certo" de se fazer teatro? Será que existe somente um teatro? Será que o que estamos fazendo hoje e chamando de teatro é de fato teatro? Será que não podemos pensar numa pedagogia do sul, ou melhor, em pedagogias do sul?

Muitas são as perguntas que emergiram ao longo desses 12 anos de docência, e precisamos tomar cuidado para que não nos deixemos levar pela ação de controlar o certo e o errado, pois isto nos faria incidir na mesma proposta catequética do colonizador europeu.

Falar de uma ação pedagógica dentro do universo artístico sem dar liberdade para o surgimento de antíteses, que se contrapõem ou que abrem brechas no pensamento original seria ir contra a própria pedagogia, a própria arte e o próprio teatro. Precisamos abraçar as pedagogias do sul e olhar para elas com o devido cuidado, pois há tesouros que os colonizadores não conseguiram usurpar, há tesouros que estão escondidos dentro de nós.

Estamos vivendo num mundo onde somente aqueles que atingem grandes feitos são reconhecidos, e o artista às vezes sucumbe à demanda do mercado e deixa de lado o seu processo de pesquisa e de descobertas pessoais. Vivemos um período de cobranças, onde há pouco espaço para o erro e para as perguntas; temos que mostrar resultado aos órgãos de fomento e por isso, às vezes, atropelamos a nós mesmos.

Entretanto, vale destacar que o artista recria o mundo através da arte, lendo-o de forma simbólica e ampliando o significado da vida. Se a vida deixou de pulsar e de fazer sentido, é hora de reagir e ampliar o significado das nossas ações; é hora de recriar o mundo, de apresentar novas leituras sobre ele e de produzir novos símbolos. É hora de produzir junto, considerando as nossas heranças européias, indígenas e todas aquelas que trazemos conosco.

Pensar uma ação pedagógica conjunta entre o professor e o aluno, entre o ator e o diretor é ampliar o significado da vida e criar espaço para o surgimento do novo. Precisamos romper com o paradigma de que ensinar teatro é transferir uma técnica ou um conhecimento a alguém, precisamos alargar as fronteiras e olhar para os brasis que existem ao nosso redor.

E se recordarmos das palavras de Paulo Freire que diz que: "ensinar não é transferir conhecimento, mas criar as possibilidades para sua própria produção ou a sua construção" (FREIRE, 1996, p. 47), se pensarmos desta forma, podemos criar novas possibilidades de produção e de construção de

Revista Moringa - Artes do Espetáculo, João Pessoa, UFPB, v. 9 n. 1, jan/jun 2018, p. 55 a 65

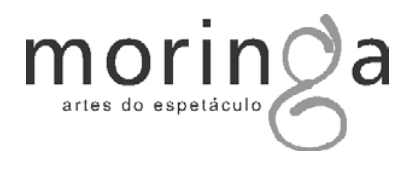


um saber teatral, não aquele arraigado nos modelos do teatro europeu, mas aquele que usa os modelos para transcender a ideia original e propor um teatro a partir de uma realidade epistemológica do sul, dialogando com a realidade na qual estamos inseridos, no nosso caso, a realidade de um nordeste múltiplo, plural e miscigenado.

Recebido em: 17/03/2018

Aceito em: 28/04/2018

\section{Referências Bibliográficas}

ARTAUD, Antonin. O Teatro e seu Duplo. São Paulo: Martins Fontes, 1993.

BACHELARD, Gaston. A água e os sonhos: ensaio sobre a imaginação da matéria. São Paulo, Martins Fontes, 2013.

BARBA, Eugenio e SAVARESE, Nicola. A Arte Secreta do Ator: Dicionário de Antropologia Teatral. São. Paulo: É Realizações, 2012.

BÉLIÈRES, Patricia; CANCELA, Alejandro; SÁNCHEZ, Rodolfo. El cantante popular y la interpretación: Una proposta metodológica integradora de saberes. Buenos Aires: Melos, 2013.

BRONDANI, Joice Aglae. (org.) Grotowski estados alterados de consciência: teatro, máscara, ritual. São Paulo: Giostri, 2015.

FREIRE, Paulo. Pedagogia da Autonomia: saberes necessários à prática educativa. São Paulo: Paz e Terra, 1996.

GROTOWSKI, Jerzy; POLASTRELLI, Carla; FLASZEN, Ludwik. O Teatro Laboratório de Jerzy Grotowski 1959-1969. São Paulo:
Fondazione Pontedera Teatro, Editora Perspectiva, 2007.

HUIZINGA, Johan. Homo Ludens: o jogo como elemento da cultura. São Paulo:

Perspectiva, 2010.

JAPIASSU, Ricardo. Metodologia do Ensino do Teatro. Campinas, SP: Papirus, 2001.

JUNG, Carl Gustav. Os arquétipos e o inconsciente coletivo. Petrópolis: Vozes, 2012.

LARROSA, Jorge. Pedagogia Profana: danças piruetas e mascaradas. 4. ed. Tradução de Alfredo Veiga-Neto. Belo Horizonte: Autêntica, 2006.

LOPES, Joana. Pega Teatro. Campinas, SP: Papirus, 1989.

RANCIÈRE, Jacques. O Mestre Ignorante: cinco lições sobre emancipação intelectual. Tradução de Lilian Valle. Belo Horizonte: Autêntica, 2002.

SANTOS, Boaventura de Sousa; MENESES, Paula Maria (org.). Epistemologias do Sul. Coimbra: Edições Almedina/CES, 2009. 
$\operatorname{moring} a$ 